\title{
A Mobile Money Solution for Illiterate Users
}

\author{
Woldmariam Mesfin \\ Addis Ababa Univ. \\ Addis Ababa, \\ Ethiopia \\ mesfinfw@gmail.com
}

\author{
Tor-Morten Grønli \\ Westerdals Oslo ACT \\ Faculty of Technology, \\ Mobile Technology Lab \\ Oslo, Norway \\ tmg@westerdals.no
}

\author{
Gheorghita Ghinea \\ Brunel University \\ London, UK \& \\ Westerdals Oslo ACT \\ Faculty of Technology \\ george.ghinea@brunel.ac.uk
}

\author{
Muhammad Younas \\ Oxford Brookes \\ University \\ Oxford, UK \\ m.younas@brookes.ac.uk
}

\begin{abstract}
Existing mobile money platforms have text based interfaces and target literate people. Illiterate people, without the assistance of literate individuals, cannot use such platforms. Applying user-centered requirements gathered in an Ethiopian context, this paper presents the design and development of a mobile money solution that targets illiterate people. Particular emphasis is given to how illiterate users deal with cash money in their everyday life and how such practices can be mapped into financial technology design. Given the ubiquity of mobile telephony in Africa, our solution is based on the widely available, relatively inexpensive and open source Android mobile web platform. The proposed system enables illiterate individuals to count money bills, while providing the facility to accept and make payments. In so doing, we provide an example of how a pervasive technology such as smartphones can empower a hitherto often neglected user category of illiterate users.
\end{abstract}

Keywords-component; Mobile money architecture, web, mobile web, illiterate users, digital money, rural application development

\section{INTRODUCTION}

Mobile phone usage is on the rise among rural Ethiopians. Even in villages without electricity, mobile phone ownership is surprisingly widespread. The primary use of mobile phones is to reduce money spent on transportation costs, to meet families in urban and other rural areas, and to get updates about market prices. People are quite aware of the utility of mobile phones and even non-owners easily describe how they would make use of it, if they had one. However, there is a problem of how to operate and use. Most old people generally need the assistance of others to make a phone call and to answer incoming calls. Literacy wise, over $70 \%$ of the adult populations living in rural areas of the country are functionally illiterate and uneducated. One in every two adults cannot read or write and the situation is worse for adult women. Many of them have no level of textual literacy, and they have no prior exposure to computing technology.

As described, Africa is a success story for mobile telephony. In the space of a generation, Africans throughout the continent have adopted the technology, across all strata of society, rich and poor. It is not uncommon for remote and rural areas to be bereft of fixed line telephony, yet have cellular network coverage. Unsurprisingly, a cellular handset represents the most popular (sometimes unique) ubiquitous computing device that the rural population has.

Ubiquitous computing is computing that happens everywhere and anywhere. However, this does not necessarily mean that it will be embraced by everyone and anyone. Indeed, many (if not most) applications (apps) available on mobile platforms nowadays assume some degree of user literacy in their design and implementation. Moreover, in respect of some category of apps - mobile money (m-money) apps in our case - the implicit assumption of the interface is that users will be literate. What happens, though, with illiterate users?

Adding complexity to the problem of illiteracy, there are many languages in the country of Ethiopia, predominantly, Amharic, Oromigna, Tigrina, Somali, and Guaragigna. A feature which challenges digital communication. For example, while transacting, an Amharic speaker can communicate with an Oromigna speaker through symbols like (showing money bills) or through some intermediaries that speak both languages. Colour and materiality of money notes has a dual purpose: as a means to identify among currency notes- by illiterate individuals and as a means of communication-when people speaking different language meet for transaction. A merchant, who is unable to say that the price of an item is 100 USD, can pick up a 100 USD banknote and show it to a customer. This enables the customer to understand what the merchant is trying to say. Thus, the physicality of money bills also enables illiterate individuals to move money around and undertake simple mathematical operation.

Illiterate users everywhere, we contend, are excluded from accessing (m-money) apps through the lack of an appropriate interface. This is a pity, as m-money apps, such as M-PESA in East Africa and GCASH in the Philippines, [1] have been particularly successful in employing a pervasive technology to enhance the levels of financial inclusion, especially in rural areas with little or no banking/financial infrastructure being available. 
Irrespective of the reported success of such m-money systems in rural communities, a close examination of the practices and services reveals that existing solutions cannot be used by rural illiterate users, unless supported by literate individuals, as exemplified for instance through Figure 1.

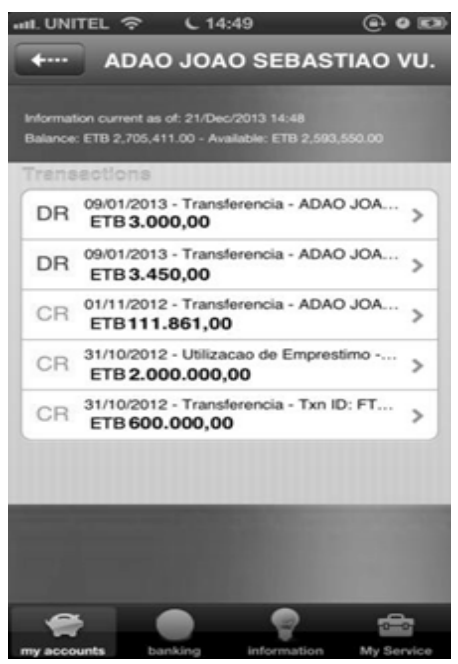

Figure 1 M-Pesa application

The reality on the ground and claims reported in the literature and media are thus quite different - as a nonnegligible category of users - the illiterate - are still essentially barred from using such apps by the lack of an effective interface [2].

In this paper, we address this issue and suggest a solution for an m-money application geared exclusively towards illiterate users, based on their observed cash-based practices in rural Ethiopia. Accordingly, the structure of this paper is as follows: Section II discusses problems of existing mobile money solutions, Section III is about design considerations of our solutions that targets illiterate users, Section IV details our system design, while Section V discusses the implication of our work, section VI discusses limitations and in section VII we conclude the paper and suggest future pursuits that our research opens.

\section{APPLICATION ARCHITECTURE AND DESIGN}

\section{A. Money Representation Style}

The way existing m- money solutions represent money in mobile phones (as a positive rational number) is an obvious barrier to illiterate users. This is compounded by the fact that each country in the world has money bills with different metadata elements embedded in them. Metadata elements have different purposes and functionalities, which vary from country to country. For example, in Ethiopia money bills are color coded and enable illiterate individuals to differentiate between the various denominations of the bills. Moreover, countries can embed (print) images and or icons reflective of their respective national identities.

\section{B. Banking Infrastructure}

Existing architectures require transacting parties to have bank accounts, which is not the case in many rural areas, Ethiopia being no exception. The majority of the Ethiopian poor, be they in urban or rural areas, as well as most rural people have no access to financial institutions like banks, microfinance organizations, and insurance companies [3] [4] [5]. In addition to this, using bank accounts for micropayments is infeasible and inappropriate [6].

\section{Digital Liquidity}

One of the key requirements for the existence and flourishing of a mobile payment ecosystem is digital liquidity [11], [12]: that is, the ability of the local economy to support mobile money staying digital, without converting it into cash and then into digital money. For this to happen, the ecosystem demands different requirements: a dramatic increase in the number of places where a mobile money user can make mobile payments without the need to convert to its cash equivalent; that individuals transact with digital money irrespective of their digital literacy, and that such transactions are done easily and at minimum cost.

\section{MNO-centric payment models}

Existing bank account and mobile network operator (MNO)centric payment models and architectures are also inappropriate for proximate (face to face) payments. The cost of subscribing to payment service providers (mobile network operators, banks, or any other third party) can also be a discouraging factor for people, particularly as most live on less than \$2 a day [27]. Moreover, there is no need to incur SMS costs for proximate (face to face) payments, as well as micro-payments and transfers that happen, say, in shops. 


\section{E. Existence of network agents}

The involvement of network agents, the place where cash is converted into digital money and vice versa, is not convenient for illiterate rural people. They usually run out of liquidity, or are the lump sums of money they handle make them a prime target for robbers. Limitations of NFCbased solutions

Even though international trials have proved that near field communication (NFC)-based mobile payments are both efficient and convenient in the eyes of the consumer, their use on the African continent has been insufficiently practiced [28]. Moreover, existing NFC-based applications do not consider the transaction and money practices prevalent in rural communities- and especially of the (majority) illiterate users in such communities.

\section{F. Money is not homogeneous}

Existing m-money applications do not consider the transaction and money practices prevalent in rural communities- and especially the (majority) illiterate users in such communities. Existing solutions consider money as a homogeneous item. This is not the case, however, as has been pointed out in the sociology, anthropology, and behavioral economics literature [7], [8], [9] and [10]. Based on the assumption that money is 'information' and can be transferred, stored, and used digitally [13], [14]; we believe that the involvement of any third party is a cost to users which can be eliminated from the transaction and transfer chain. In short we wanted to ask what it takes to use digital money with out converting it into cash (material money). Are there any mechanisms through which information technology can simplify the use and management of digital money for illiterate users? Our real life exposure to the everyday money practices of illiterate users in Ethiopia motivated us to look the situation from the research perspective.

\section{DESIGNING For ILliterate USERS}

\section{A. Money Practices of Illiterate Users}

It is important to consider the main implications for designing for illiterate users. Several aspects, taken as granted for everyday users are not any longer viable solutions. New resolutions must be sought in order to facilitate for this group of users. Our previous research and observation [2] and [15] about the different money practices of the illiterate revealed that:

1. They differentiate money bills based on the color and the different images and icons printed on each and every type of money bill. As Ethiopian money bills of Ethiopia are color-coded and each bill has its own images, illiterate individuals easily differentiate between money bills.

2. The physical or material nature of money bills enables illiterate users to do simple mathematical operations, such as sharing a lump sum of money. For example, if 5 illiterate individuals want to share 100USD equally among themselves, they do do this not by calculating with a pen and paper, but rather by placing money bills into 5 stacks and distributing the 100USD in an iterative, roundrobin, manner. Whenever they do find the distribution is not even, they break some bills into smaller denominations and continue with the iterations.

3. Illiterate users know how much money they have by counting money bills in their possession (i.e. they know how to count, although are not able to read or write). Moreover, as they cannot write this amount, the only way of remembering it is by committing it to memory.

As a result of the above practices, we have adopted our design concepts and propose the following design, depicted in Figure 2.

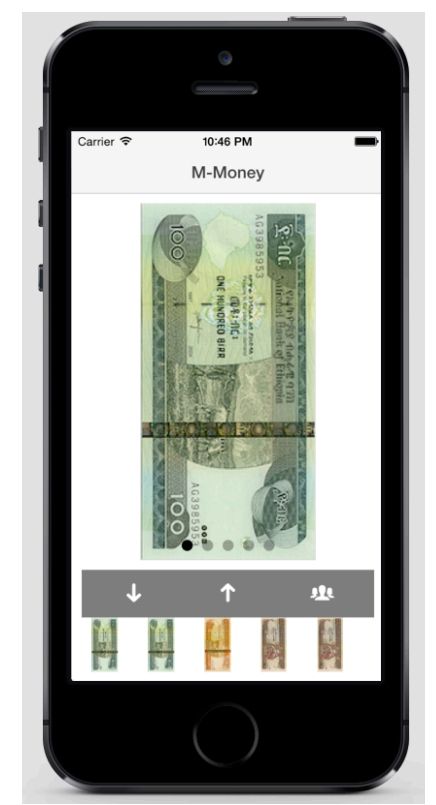

Figure 2 Implementation of swiping through a stack of bills

\section{B. Text-free interfaces:}

An alternative approach to deal with money digitization from the point of view of illiterate individuals is the use of natural interfaces, which in our case entails the use of photos of money bills. This enables illiterates to easily differentiate among money bills, build trust on the system, and learn the application easily. One way or the other, a 
good application for illiterate users is one that enables them to do many of the things they already do with material money. For example, they could view their balances in their phone by counting digital money bills, make money changes in their phone, keep some money categories separate etc. Studies by [16, 17, 18 19] also revealed that illiterate users are comfortable with non-text designs over text-based designs. Unlike previous mobile money solutions and platforms, we do not use textual-based interface mechanisms. Rather, we have used the images of money bills as it is. By doing this, we also made the transitions among money bills simple. Users can simply swipe in order to navigate and select money bills they would like to use or to count how many bills of a particular denomination is available in the application. The simplicity of using text free interfaces by illiterate users is already proven [15].

\section{Digital money representation:}

Unlike previous mobile money solutions that represent digital money in a positive rational number of the form $(0.89,23.87,120.90$ etc. $)$, we wanted to map the real money bills into a digital environment. For example, in Ethiopia, we have the following money bills ( 1 birr, 5 birr, 10 birr, 50 birr, and 100 birr1, see Figure 3).

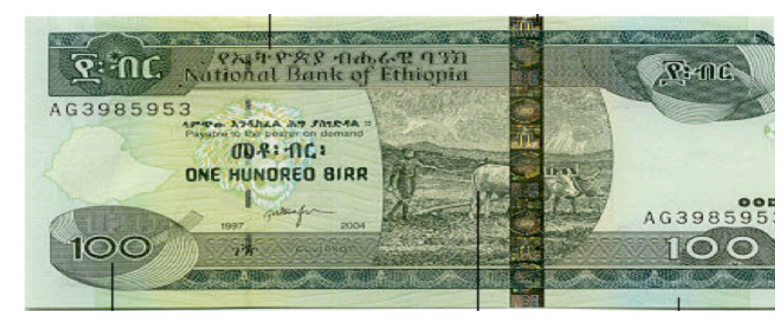

Figure 3 Ethiopian 100 Birr note

These values can therefore be brought to the top of the interface and be activated by swiping through them, one after the other. It is similar to swiping through stacks of digital photos in our mobile phones. In doing this, we hope that illiterate users can easily deal with their digital money.

\section{Compartments/placeholders:}

From the everyday money handling practice of individuals we have learnt that illiterate people sort money based on its denomination. In the case of Ethiopian money, they sort money starting from the one birr money bill all the way to a hundred birr money bills. Such sorting enables counting and doing basic mathematical operations by illiterate individuals. Besides, sorting also facilitates the making of payments. Thus, we propose an interface incorporating compartments that hold the respective frequencies of each money bill.

\section{SYSTEM DESIGN}

Our approach builds upon the AngularJS framework [26] for heterogeneous cross-platform availability. AngularJS is an open-source framework for creating web applications, maintained by Google. A large community actively supports it and AngularJS can assist in creating single page applications with the use of HTML5, CSS3 and JavaScript on the client side. The goal of using AngularJS is to simplify the development process, focusing primarily on business logic. HTML and CSS are in accordance with (mobile) web development practices used for structure and design elements. This gives the possibilities to take advantage of an imperative programming model for the logic, and further use the declarative model for interface design.

\section{A. A Layered Architecture for M-Money}

The approach for designing the mobile web application follows the structure of model - view - controller (MVC) [21]. The classic MVC architecture is outlined in Figure 4.

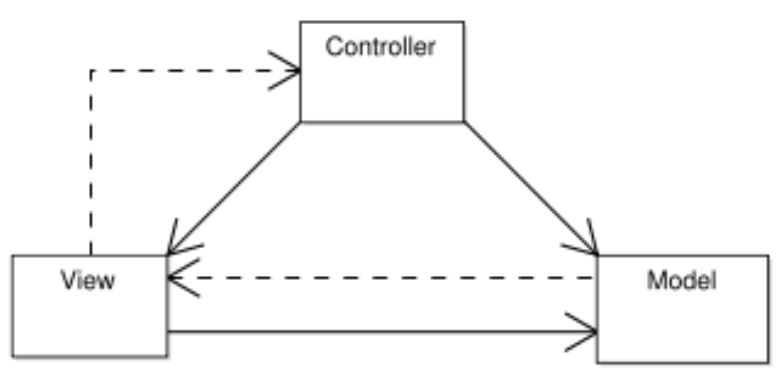

Figure 4 The MVC architecture

The MVC architecture gives the benefit of fewer dependencies between code modules leading to improved maintainability and easier separation of concerns. We have chosen to let the model contain the data to be stored, the money bills and entity values. The controller is in charge for implementing the two-way binding between the view and the model. This implements the dynamic relationship between user driven changes in the view to be mirrored in the data (model) and if data are internally manipulated (i.e. transferal of money) the view will be accordingly updated. The view further contains all structural logic for presenting the interface to the user.

\footnotetext{
${ }^{1} 1 \mathrm{USD}=20$ birr (current exchange rate)
} 


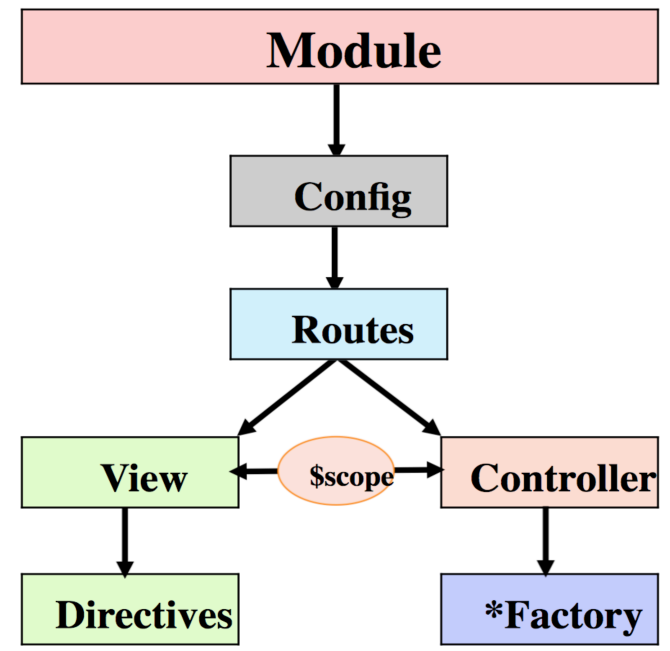

Figure 5 System architecture

Figure 5 displays the system architecture as implemented in the system. The scope is the glue connecting the view and the controller based on the given scope as identified in the directive. Further, the controller keeps the view lightweight by holding the code behind it and the module represents the state of stored entities. User interaction elements packaged as reusable directives forms the basis in our solution, allowing for a touch only, graphical interface. The business code for completing transfers is wrapped in view code behind files, the controllers. Local money storage is laid out through module elements together with associated entities such as currency, topic and user entity. The system flow is controlled through the preconfigured routes recognized by the http call, invoking server only at times necessary.

\section{B. M-Money implementation}

Our prototype implementation demonstrates the heterogeneous mobile web application running on a smartphone. The interface in Figure 6 presents the digital money representation, the user's digital wallet, where the user can swipe through his stack of bills.

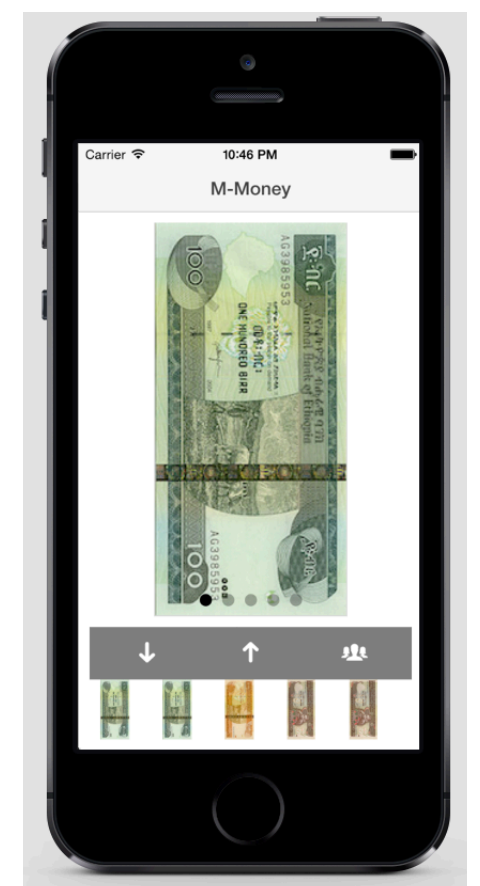

Figure 6 Swiping through a stack of bills

The most important facet for the illiterate users is to be able to use an interface where the absence of text and numbers increase their ability to interact and perform activities. Our interface relies conclusively on image for interaction elements. In the wallet, the user can swipe through his/her stack of digitally represented bills and inspect them separately.

For illiterate users a main function to perform in the mobile money solution is to be able to transfer funds for different purposes. The user would like to be able to set aside money for different occasions such as family, religious purposes or general saving. Such a feature is important, especially given the fact that these users often engage in commercial activities such as trading at a market, selling products, faceto-face money transfer and micro transactions. 


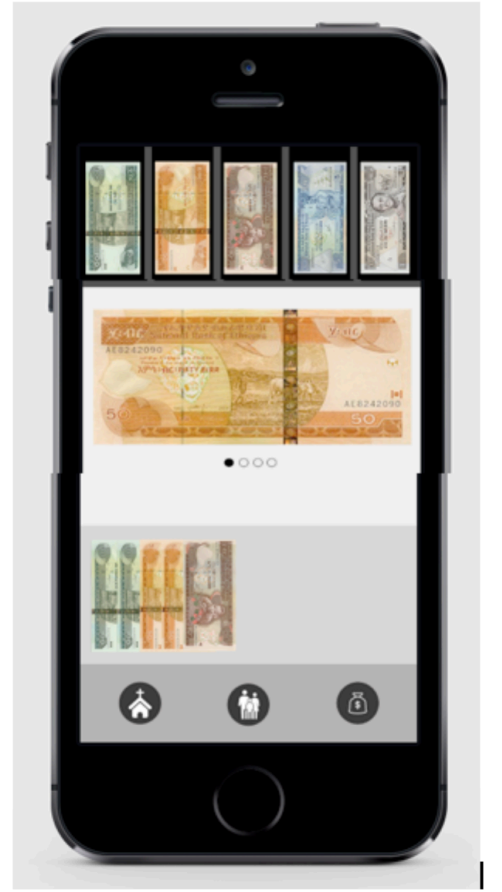

Figure 7 Interface for saving money for a given purpose

Figure 7 shows the savings screen as laid out for a user. At the top level, the different compartments hold the different kind of bills available in Ethiopia, which enables easy selection of a kind. If the user's total digital wallet content is for instance below 100 birr (largest bill), this bill compartment would be gray. The user could choose to select five 10 -value bills or one 50 -value bill, and both options would deduct the amount of 50 birr from the wallet. If now the remaining value were below 50 , this compartment would be gray as well. When selecting a colored bill, part of the interface shows the selected bill, represented horizontally. The user can swipe through the to count his/her number of bills of this kind, as well as look at the indicator below the bills which represents the number of bills as long as they are fewer than 10. From this section the user can drag a note to the grey area next to the footer to add it to his/her current selection. When the user is happy with the selection s/he taps the respective icon for saving it for religious purposes, for family, or for personal saving, each represented by an icon in the footer.

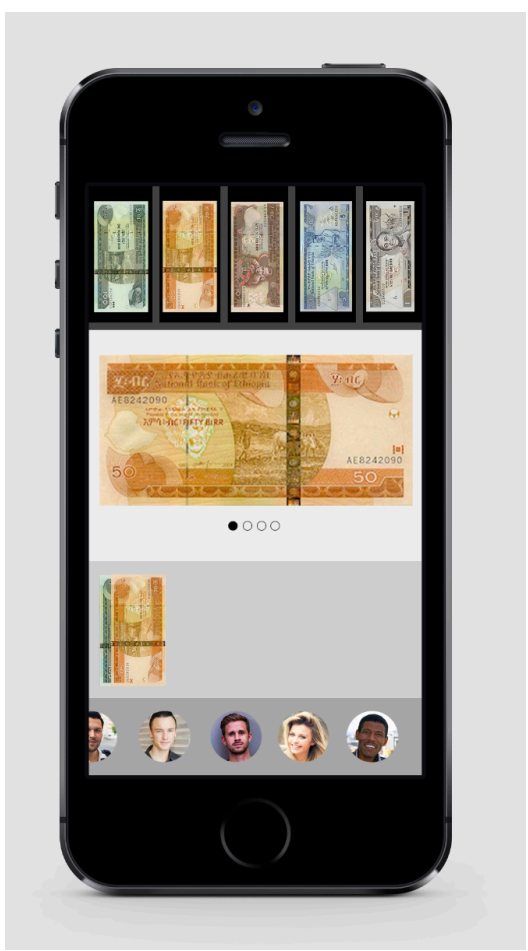

Figure 8 Interface for money transfer to contacts

Figure 8 shows the interface for transferring money from the user's wallet to one of the registered contacts. As for the interface for saving money this interface is similarly built. When selecting a colored bill, part of the interface shows the select bill, represented horizontally. The user can swipe through the to count his/her number of bills of this kind, as well as look at the indicator below the bills, which represents the number of bills as long as they are fewer than 10. From this section the user can drag a note to the grey area next to the footer to add it to his/her current selection. When the user is happy with the selection s/he taps the respective contact to transfer money. A confirmation dialogue is presented so the user can confirm the selected contact, and complete the transaction.

\section{PROTOTYPE EVALUATION}

Evaluation is a fundamental part of human computer interaction and interface design. Designers attempt to understand the needs of some audience and then formulate system designs to meet those needs. The focus of almost all evaluation in human computer interaction has been on how well someone can complete some specified task using the technology being evaluated. During evaluation, common measurements include: time to complete the task, error rates, ease of learn-ability, completeness, simplicity, elegance, understandability, and ease of use [20]. 
In the current design science paradigm, evaluation of artefacts is based on "functionality, completeness, consistency, accuracy, performance, reliability, and usability, fit with the needs or goals" [21]. While these qualities of artefacts will continue to be important, the evaluation of digitalized everyday artefacts will also require another important criterion, desirability and some other criteria as related to the theory of designing socio-technical systems. Here desirability requires us to consider humanistic values, such as, aesthetics and ergonomics, among other factors as we evaluate digitalized artefacts [22].

The evaluation we followed is a task centred walk-through, as proposed by [23]. Users were given a task to perform and their performance is observed and recorded. In a walkthrough, one tells a concrete story about what a particular user would do and is able to observe that user step by step when performing his/ her particular task using the interface [24]. Walk-throughs are an excellent low-cost way to evaluate interface, as it enables to quickly discover trouble spots users have. Even though walk-through can be done by designer him/herself, it would be best if done by end users and thus, illiterates were used to evaluate this prototype.

Activity focused research methodologies, such as observations of user interactions and interviews [25] are a good approach to understand users interface and interaction problems. This includes the analysis of how they learn, use, and move from screen to screen. This information is good for people-centered design. Through such and observation technique it is possible to record participants emotional reactions, such as confusion or frustration.

\section{LIMITATIONS}

We acknowledge a limitation in the paper from the lack of formal, large-scale user evaluation. For future work this will be an important aspect to verify the validity of results and conclusions in a large population as well.

\section{CONCLUDING Discussion}

In order for digital money - particularly mobile money - use to be truly pervasive, there is firstly the need for it to become a universal information utility that is of value to the majority. This in turn requires mobile money solutions to scale up and reach critical mass [12], thus enabling cashless transactions and exchanges to be easily possible. The ubiquity of mobile phone telephony in sometimes the remotest of areas makes it a uniquely suited candidate to address this challenge - a challenge compounded by the current lack of interfaces geared towards illiterate users, a sizeable community in some areas of rural Africa (and not only).
Accordingly, in this paper we have proposed and designed a mobile money system whose components and interfaces take into account the everyday money practice needs of illiterates. We believe that if support is given for the illiterate people through appropriate system and interfaces, they stand to benefit greatly from ICT. Consequently, we have designed and developed a prototype mobile money system that enables illiterate users to digitally transact and be able to do everything they currently do with material money.

Dematerializing cash and treating it as information will benefit the poor (many of whom also happen to be illiterate in the case of Ethiopia), - that is, the people most likely to have no access to financial institutions, business, and governments [12]. Individuals, who will now be able to send money to each other anytime and to access their money ubiquitously, businesses, who can have real time information about their financial status, and governments, who are now better able to control expenses related to administering programs dealing with micropayments, social welfare payments, and the like, all benefit when money goes digital.

Like other development researchers, it is our strong belief that appropriate mobile payments ecosystems have the potential to transform how people access financial services and move them out of poverty, in the process helping them to hold on to economic gains.

Future work, will involve a continued development of the money application to represent a digital wallet, purchasing and money transfer system. Large-scale user evaluation is to be performed with the citizens in rural Ethiopia and inclusion of additional supportive techniques for illiterate users such as complete audio-based interface.

This is the initial start of the field trial of the proposed system and more countries and regions should be added in the future. The proposed system is flexible to grow and scale in accordance with any currency system featuring color-coded or icon-based notes or coins. We encourage future development in the area and think such use of technology has permanent place in future solutions to enrich the world of illiterate users.

\section{REFERENCES}

[1] I.Mas and O. Morawczynski. Designing Mobile Money Services Lessons from M-PESA. Innovations 4.2 PP. 77-91, 2009.

[2] Mesfin, W., Ghinea, G., Atnafu, S. and Gronli, T-M. Mobile Money System Design for Illiterate Users in Rural Ethiopia. 
In proceedings of Third International Human Computer Interaction Conference, DUXU, Heraklion, Crete, Greece, June 22-27, 2014, Part III, PP. 482-491.

[3] Collins, D., Morduch, J., Rutherford, S. and Rutheven, O.. Portfolios of the poor. Princeton, NJ: Princeton University press, 2009, PP, 1-174.

[4] Dhakhwa, S., Hall, P., Ghimire, B., Manandhar, P. and Thapa, I. Human-Computer Interaction, Part I, HCII 2007, Lecture Notes in Computer Science 4550, pp. 721-730.

[5] R.Duncome, and R. Boateng. Mobile phones and financial services in developing countries. Working paper No 37. Centre for development informatics, institute for development policy and management, 2009.

[6] S. Rutherford. The Poor and their Money. An essay about financial services for the poor. Institute for development Policy and Management University of Manchester, UK, 1999.

[7] G. Weidong. "Design of architecture for mobile payments system" Chinese Control and Decision Conference, 2008, PP.1732-1735.

[8] N.Chidembo. Exploring Consumer Adoption of NFC enabled Mobile Payments in South Africa. Master thesis, University of Pretoria, South Africa, 2009.

[9] B. Maurer. The Anthropology of Money. Annual Review of Anthropology. Vol. 35, PP.15-36, 2006.

[10] S. Singh. Marriage Money: The social shaping of money in marriage \& banking. St. Leonards, Australia: Allen \& Unwin, 1998.

[11] A.Zelizer. The social meaning of money: Pin money, pay checks, poor relief, and other currencies. Princeton University Press. New Jersey, 1997.

[12] R. Byler. What is Money? Mid-South College Computing Conference, 200

[13] A.Gellion. Personal Money Management Products for a Cashless Society. Master Thesis at the University of Calgary, Canada, 1999.

[14] I.Mas and N.Sullivan. Mobile money as Information Utility That Touches Everyone. Refining the Vision for Financial Inclusion. Innovations, volume 6, number 4, 2012

[15] W. Mesfin, G. Ghinea, S.Atnafu. Open air market and mobile money information system requirements. Proceedings of 2013
International Conference on ICT for Smart Society (ICISS). Jakarta, Indonesia, IEEE 2013, PP. 1-6.

[16] Grisedale, S., Graves, M., \& Grünsteidl, A. (1997). Designing a graphical user interface for healthcare workers in rural India. In Proceedings of the ACM SIGCHI Conference on Human factors in computing systems (pp. 471-478). ACM.

[17] Medhi, I., Sagar, A., \& Toyama, K. (2006). Text-free user interfaces for illiterate and semi-literate users. In IEEE International Conference on Information and Communication Technologies and Development, pp. 72-82.

[18] Medhi, I., Gautama, S. N., \& Toyama, K. (2009). A comparison of mobile money-transfer UIs for non-literate and semi-literate users. In Proceedings of the ACM SIGCHI Conference on Human Factors in Computing Systems (pp. 1741-1750).

[19] Parikh, T., Ghosh, K., \& Chavan, A. (2003, November). Design studies for a financial management system for microcredit groups in rural india. In ACM SIGCAPH Computers and the Physically Handicapped, Volume 73-74, pp. 15-22.

[20] March, S. T., \& Storey, V. C. (2008). Design science in the information systems discipline: an introduction to the special issue on design science research. Management Information Systems Quarterly, 32(4), 6.

[21] von Alan, R. H., March, S. T., Park, J., \& Ram, S. (2004). Design science in information systems research. MIS quarterly, 28(1), 75-105.

[22] Yoo, Y. (2010). Computing in Everyday Life: A Call for Research on Experiential Computing. Mis Quarterly, 34(2), 213-231.

[23] Nielsen, J., \& Mack, R. L. Usability inspection methods, 1994. In Conference Companion on Human Factors in Computing Systems.

[24] Carroll, J. (2000). Making use: Scenario-based design of human-computer interactions. Cambridge, MA: MIT Press.

[25] Veryzer, R. W., \& Borja de Mozota, B. (2005). The Impact of User Oriented Design on New Product Development: An Examination of Fundamental Relationships*. Journal of product innovation management, 22(2), 128-143.

[26] Google, AngularJS. Available online from [https://angularjs.org/], 2014

[27] Kendall, J., Maurer, B., Machoka, P., \& Veniard. C. (2011). An emerging platform: From money transfer system to mobile money ecosystem. innovations, 6(4), 49-64.

[28] Chidembo N. (2009). Exploring Consumer Adoption of NFC enabled Mobile Payments in South Africa. (Unpublished Master thesis, University of Pretoria). 